\title{
Mutual Coupling Effect on Ultrawideband Linear Antenna Array Performance
}

\author{
Osama Ahmed ${ }^{1}$ and Abdel-Razik Sebak ${ }^{1,2}$ \\ ${ }^{1}$ Electrical and Computer Engineering Department, Concordia University, Montreal, QC, Canada H3G 1M8 \\ 2 PSATRI, KSU, Riyadh 11451, Saudi Arabia
}

Correspondence should be addressed to Osama Ahmed, osama_m_h@yahoo.com

Received 24 April 2011; Accepted 12 June 2011

Academic Editor: Marek E. Bialkowski

Copyright (C) 2011 O. Ahmed and A.-R. Sebak. This is an open access article distributed under the Creative Commons Attribution License, which permits unrestricted use, distribution, and reproduction in any medium, provided the original work is properly cited.

\begin{abstract}
This paper studies the mutual coupling effect between array elements of two- and four-element ultrawideband (UWB) linear arrays on their performances. For simplicity, it is assumed that both antenna arrays are fed by independent microstrip lines with the same power amplitudes and equal phases. From our study, array bandwidth improvement is achieved for both array types when the mutual coupling is strong enough or interelement spacing is small. The mutual coupling also enhances the array realized gain especially in the midfrequency band $(5-8.5 \mathrm{GHz})$ while it deteriorates the gain outside that frequency range. Proper tuning for interelement spacing with enough mutual coupling enhances the array realized gain at most frequencies and makes it more stable across the desired frequency range. From the radiation pattern results, the grating lobes appear in UWB arrays when the element spacing is greater than two wavelengths at the upper edge frequency, $10.6 \mathrm{GHz}$, or half wavelength at the lower edge frequency 3.1 GHz. Two fabricated array prototypes with corporate feed are fabricated and tested to validate the theoretical analysis. The effect of using $T$-junction power divider is clear on the reflection coefficient $\left|S_{11}\right|$. Both numerically simulated and experimental results successfully demonstrate our analysis.
\end{abstract}

\section{Introduction}

Ultrawideband (UWB) technology has inspired many academic researchers, scientists, and industrialists since the Federal Communication Commission (FCC) announced the use of unlicensed frequency band of $3.1-10.6 \mathrm{GHz}$ for commercial communication applications in 2002 [1]. This available wide bandwidth enables UWB systems to achieve high speed and high data rates in communications applications, that is, more than $500 \mathrm{Mbps}$ [2], high accuracy in localization systems [3], or very high resolution in radars' applications [4]. The antenna is considered an important component in the UWB system, and it affects the overall performance of the system. Researchers have developed recently many different antenna designs for UWB applications with wide impedance bandwidth, linear phase, reasonable gain, and stable radiation characteristics across the whole UWB frequency band [5-8].
In certain applications such as microwave imaging, localization or radar applications, high gain is needed. Typically the UWB single antenna element has relatively low gain of order 3-4 dBi, which can be improved using antenna arrays. Antenna arrays are widely used in many practical systems to enhance gain or provide beam scanning capability. Mutual coupling among antenna elements is an important issue, and it should be taken into consideration in designing antenna arrays. Several studies have shown that mutual coupling degrades the performance of antenna arrays by modifying the array radiation pattern, $3 \mathrm{~dB}$ beamwidth, and directivity of an array [9-11]. However, mutual coupling is natural array behavior and may be used to enhance the overall array performance such as bandwidth [9]. For narrowband (NB) or single resonant antenna arrays, the element spacing should be less than one wavelength $\lambda$ at the resonant frequency $f_{r}$ to avoid grating lobes and also to keep strong enough mutual coupling among elements to enhance the overall array 


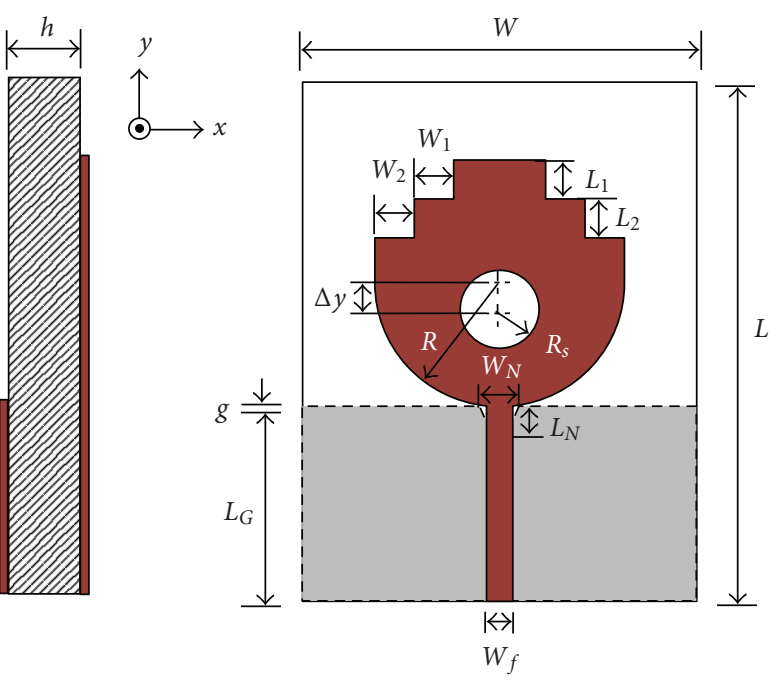

Figure 1: Geometry of a single UWB antenna element with a microstrip line feed, (a) side view and (b) top view.

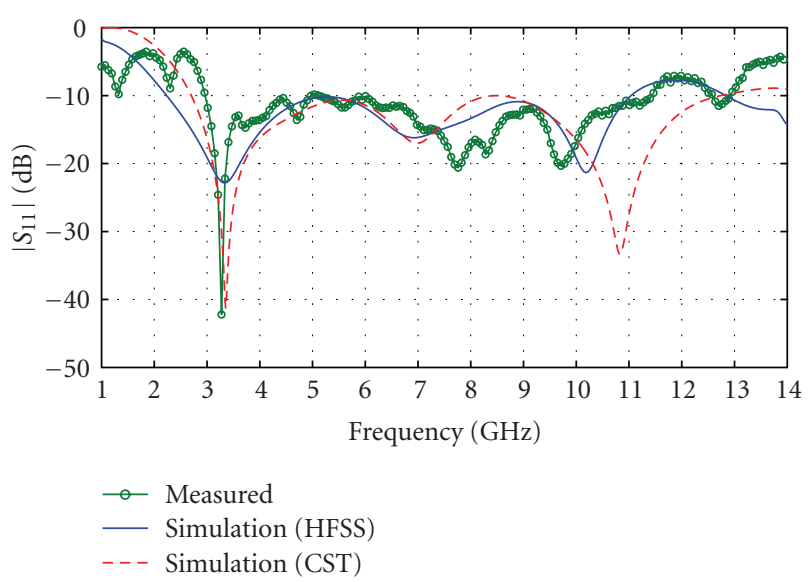

Figure 2: Measured and simulated $\left|S_{11}\right|$ for the UWB antenna element with a microstrip line feed.

performance. But for ultra-wideband (UWB) antenna arrays which operate at very large frequency bandwidth or at more than one resonant frequency, it is not clear how the element spacing should be in terms of wavelengths at the lower edge frequency $f_{L}$, center edge frequency $f_{c}$, and upper edge frequency $f_{U}$ to avoid grating lobes in the whole UWB frequency band. Extensive parametric studies should be carried out to see the effect of element spacing on antenna array performance to avoid grating lobes.

In this paper we study the mutual coupling effect on the performance of UWB linear antenna arrays. This study includes the numerical investigation of the mutual coupling effect on the array matching bandwidth, correlation coefficient, sidelobe level (SLL), and the array gain. First, twoelement UWB linear antenna array is constructed by using two identical UWB antenna elements fed simultaneously through two independent microstrip lines. For simplicity, it is assumed that the power amplitude is fed equally between

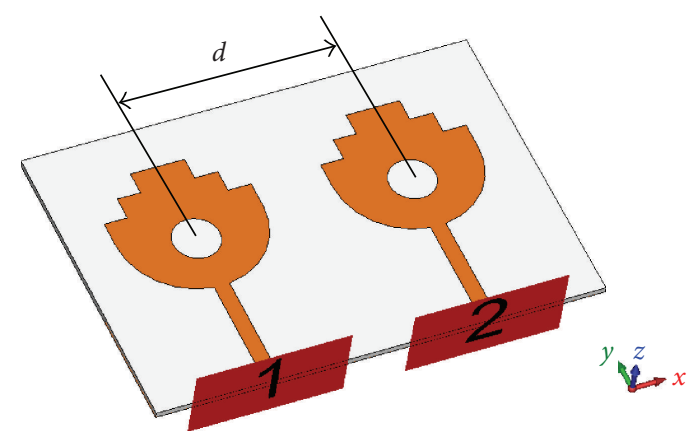

Figure 3: Two identical UWB antenna elements fed simultaneously through two independent microstrip lines.

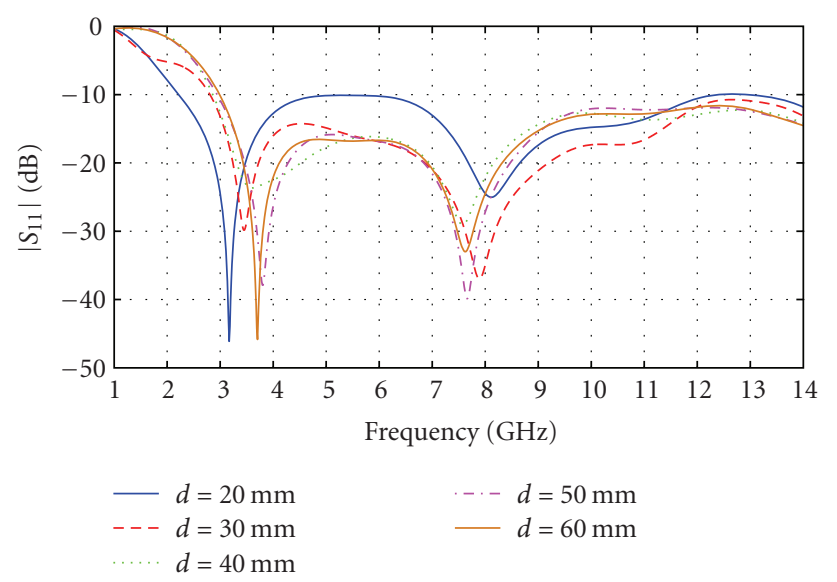

Figure 4: Simulated $\left|S_{11}\right|$ results of two-element UWB array.

TABLE 1: Dimensions of the antenna element in Figure 1.

(a)

\begin{tabular}{lc}
\hline$W$ & $30 \mathrm{~mm}$ \\
$L$ & $40 \mathrm{~mm}$ \\
$R$ & $9.5 \mathrm{~mm}$ \\
$R_{S}$ & $3.0 \mathrm{~mm}$ \\
$\Delta y$ & $2.0 \mathrm{~mm}$ \\
$L_{G}$ & $15 \mathrm{~mm}$ \\
$W_{1}$ & $3.0 \mathrm{~mm}$ \\
$L_{1}$ & $3.0 \mathrm{~mm}$ \\
\hline
\end{tabular}

(b)

\begin{tabular}{lc}
\hline$W_{2}$ & $3.0 \mathrm{~mm}$ \\
$L_{2}$ & $3.0 \mathrm{~mm}$ \\
$W_{F}$ & $2.0 \mathrm{~mm}$ \\
$W_{N}$ & $3.0 \mathrm{~mm}$ \\
$L_{N}$ & $3.5 \mathrm{~mm}$ \\
$g$ & $0.1 \mathrm{~mm}$ \\
$h$ & $0.787 \mathrm{~mm}$ \\
\hline
\end{tabular}

the two elements with equal phases. For a two-element array, the array is treated as a two-port network, and hence the reflection coefficients are approximately the linear 


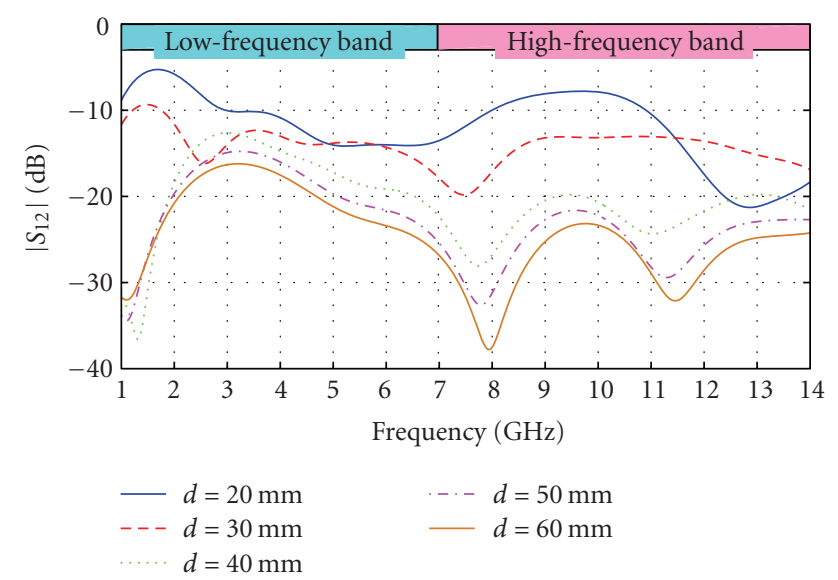

FIgURE 5: Simulated $\left|S_{12}\right|$ results of two-element UWB array.

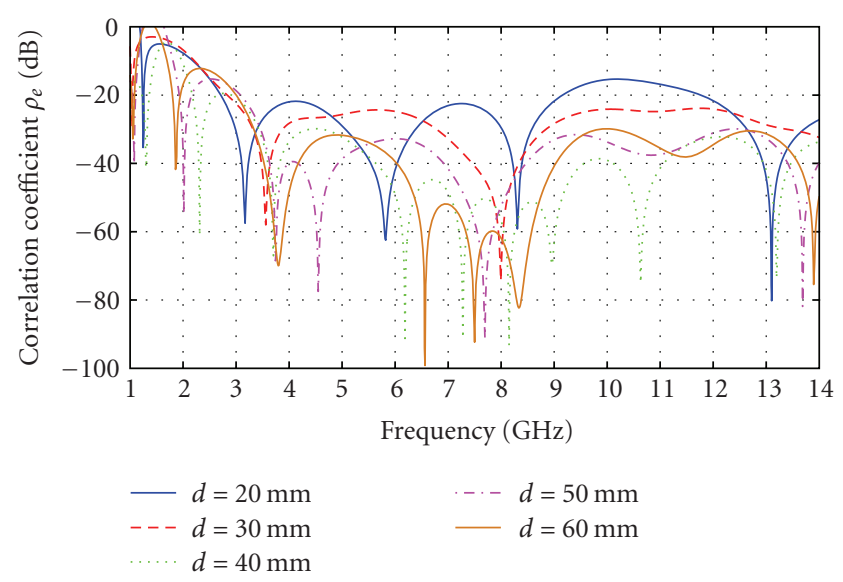

FIGURE 6: Simulated correlation coefficient $\rho_{e}$ results of twoelement UWB array.

superposition of scattering coefficients $\left|S_{11}\right|$ and $\left|S_{12}\right|$ of the array. Second, four-element UWB linear antenna array is constructed by using four identical UWB antenna elements fed simultaneously through four independent microstrip lines with equal amplitudes and phases. For a four-element array, the array is treated as a four-port network with reflection coefficient being approximately the linear superposition of scattering coefficients of the array. The theoretical analysis is carried out using Ansoft HFSS [12] which is based on finite element (FE) method and CST Microwave Studio [13] which is based on finite integration technique (FIT). While performing simulation using both HFSS and CST programs, the Rogers substrate material (RT5880) is chosen from the predefined internal library of the simulation programs. This is why the change in the relative permittivity $\varepsilon_{r}$ and loss tangent $\tan \delta$ of the substrate as a function of frequency was taken into account in the simulation, and their effect is too small to mention in this paper. For the experimental investigation, two- and four-element UWB antenna array prototypes with corporate feed using $T$-junction UWB power divider are fabricated and then tested. The measurement results agree well with the simulated ones.

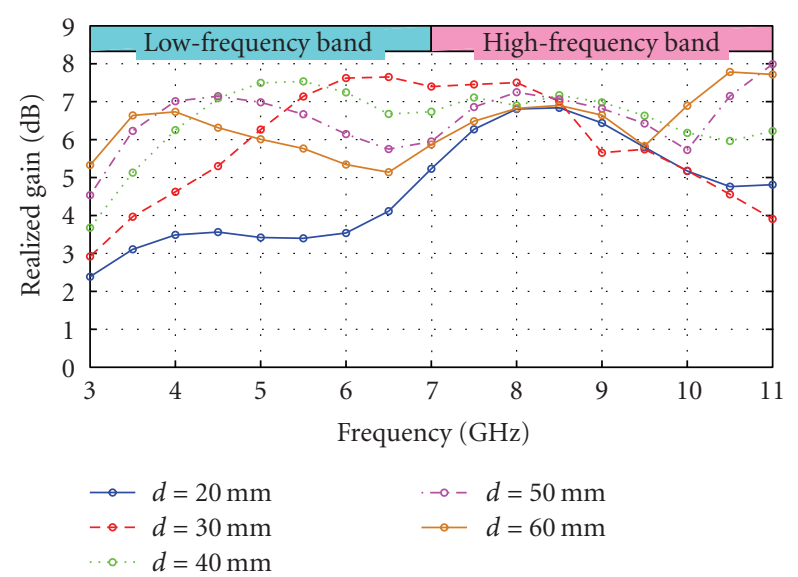

FIGURE 7: Simulated realized gain results of two-element UWB array.

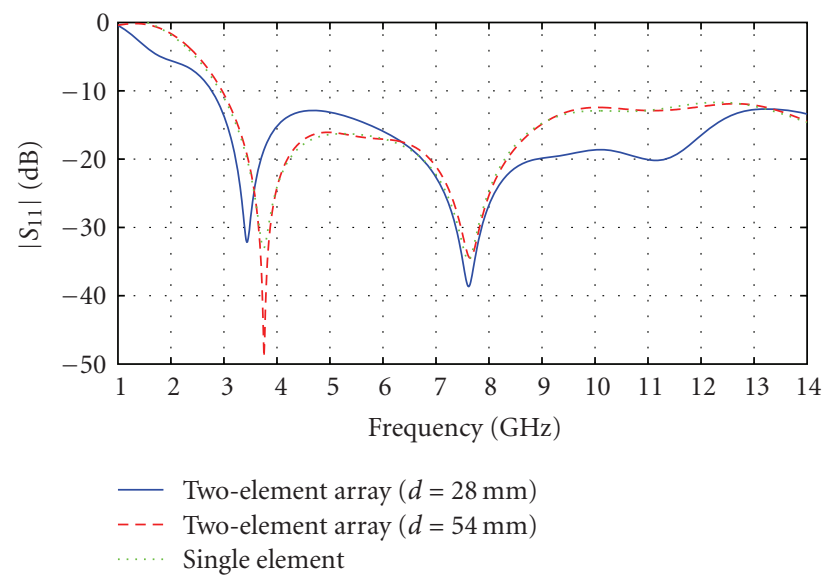

(a)

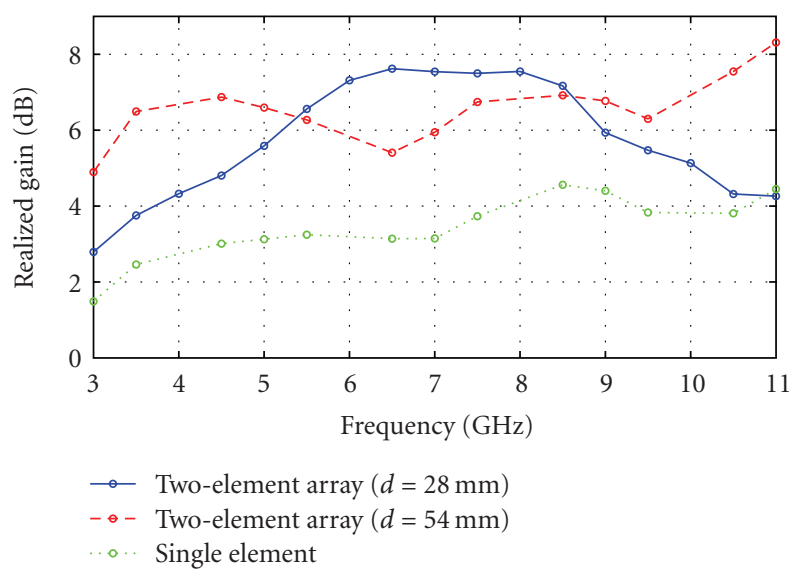

(b)

Figure 8: Simulated (a) $\left|S_{11}\right|$ and (b) realized gain curves of the two-element UWB array at different element spacing values $d$ compared to a single antenna element. 


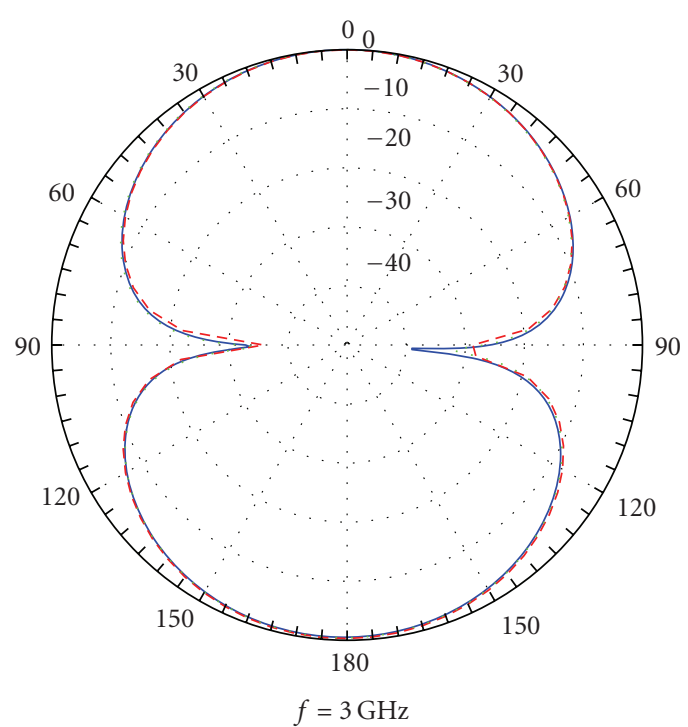

(a)

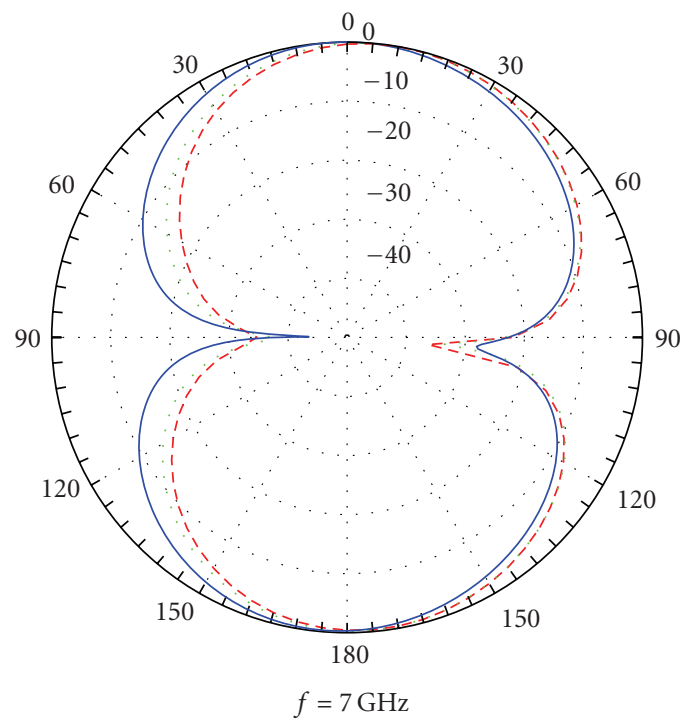

(c)

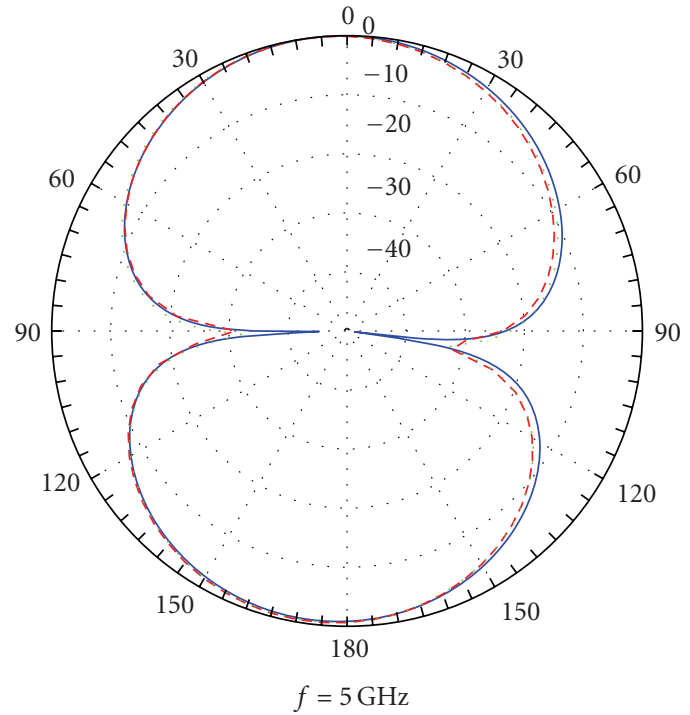

(b)

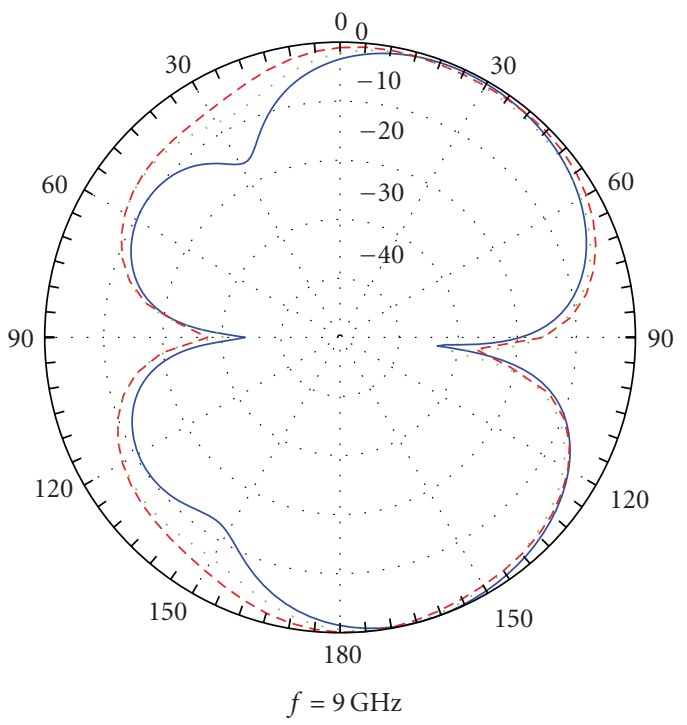

(d)

FIGURE 9: Simulated $E$-plane ( $X Z$-plane) radiation patterns for the two-element UWB array at different element spacing values $d=28 \mathrm{~mm}$ (solid line) and $d=54 \mathrm{~mm}$ (dashed line) compared to a single antenna element (dotted line).

\section{Two-Element UWB Linear Antenna Array}

We consider a two-element UWB linear antenna array as shown in Figure 3, respectively. The geometry of the UWB antenna element is presented in Figure 1 with all optimized dimensions tabulated in Table 1. The antenna element consists of a microstrip-line-fed printed disc monopole with two steps and a circular slot with a finite truncated ground plane, and both are printed on a Rogers RT/duroid5880 high-frequency laminate with thickness of $h$, loss tangent of 0.0009 , and relative permittivity of 2.2. Both simulated and measured results in Figure 2 show that the antenna element has an UWB frequency response. The antenna also exhibits dipole-like radiation pattern through the whole frequency range. Two-element UWB array, which is fed through two independent microstrip lines, is used in our study to address the effect of mutual coupling between antenna elements without taking the effect of any feed network into account. The element spacing or distance between two antenna elements is $d$. It is very clear that the element spacing $d$ mainly affects the mutual coupling between elements. So, extensive parametric studies are carried out to investigate the effect of varying element spacing $d$ on different array parameters such as matching impedance bandwidth, correlation coefficient $\rho_{e}$, and realized gain. The correlation of two antennas is evaluated from $S$-parameters according to the formula [14]

$$
\rho_{e}=\frac{\left|S_{11}^{*} S_{12}+S_{21}^{*} S_{22}\right|^{2}}{\left(1-\left(\left|S_{11}\right|^{2}+\left|S_{21}\right|^{2}\right)\right)\left(1-\left(\left|S_{22}\right|^{2}+\left|S_{12}\right|^{2}\right)\right)} .
$$




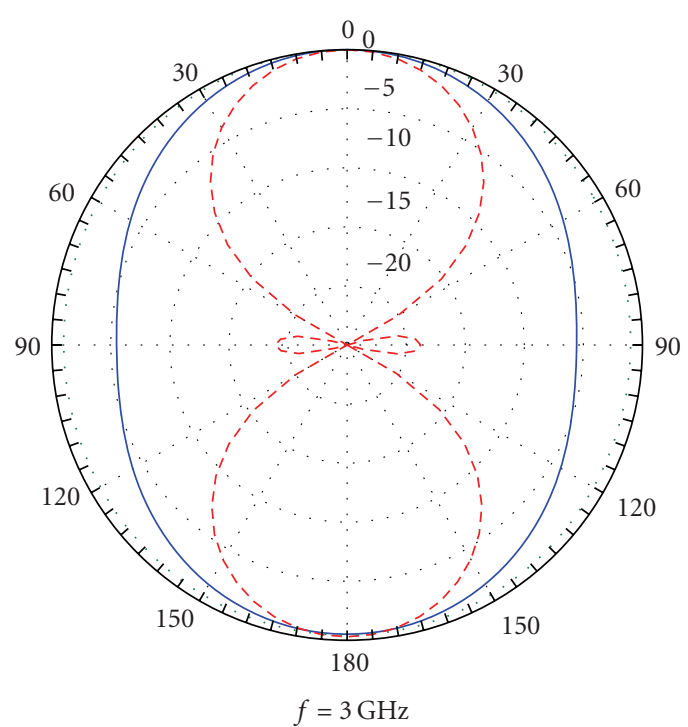

(a)

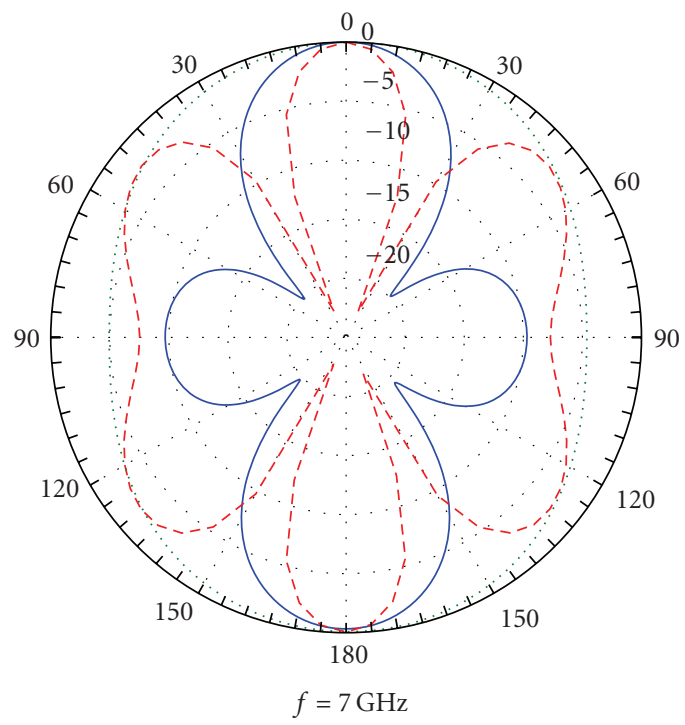

(c)

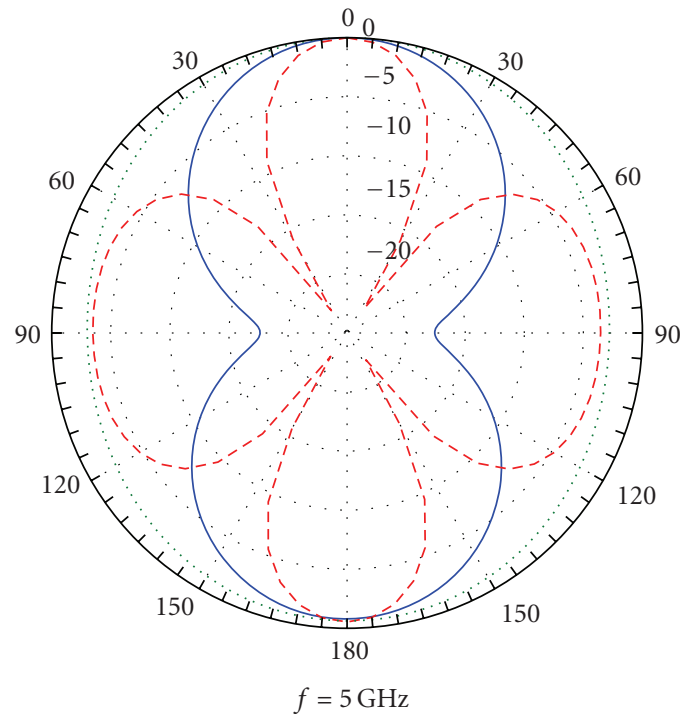

(b)

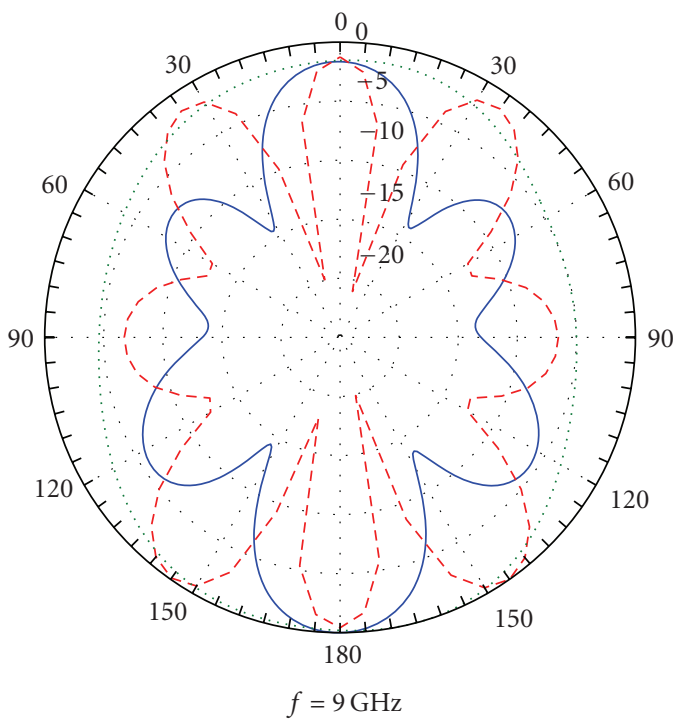

(d)

Figure 10: Simulated $H$-plane ( $Y Z$-plane) radiation patterns for the two-element UWB array at different element spacing values $d=28 \mathrm{~mm}$ (solid line) and $d=54 \mathrm{~mm}$ (dashed line) compared to a single antenna element (dotted line).

The simulated reflection coefficient $\left|S_{11}\right|$ results of twoelement UWB array are shown in Figure 4. From the results, when the element spacing $d$ is very small, that is, $d=20 \mathrm{~mm}$, the mutual coupling between antenna elements becomes very strong, and hence it strongly affects the resonant frequencies. So, mutual coupling obviously enhances the twoelement array bandwidth. By increasing the element spacing $d$, the mutual coupling between antenna elements becomes weaker, and hence its effect on the reflection coefficient $\left|S_{11}\right|$ is almost negligible.

For further understanding the effect of the mutual coupling between antenna elements on the array performance, the simulated $\left|S_{12}\right|$ is evaluated and presented in Figure 5. The isolation between the two antenna elements is improved dramatically by increasing the element spacing $d$ more than $30 \mathrm{~mm}$ especially at higher frequencies, that is, $7.0-14 \mathrm{GHz}$. This is because the mutual coupling effect is weak at low frequencies, that is, $1-7 \mathrm{GHz}$, and by increasing the frequency more than $7 \mathrm{GHz}$, the element spacing becomes electrically large with respect to wavelength, and hence the mutual coupling effect becomes weaker and isolation is improved at higher frequencies.

The correlation coefficient $\rho_{e}$ between the two antenna elements has also been studied. Figure 6 shows the correlation coefficient $\rho_{e}$ with frequency at different element spacing values $d=20,30,40,50$, and $60 \mathrm{~mm}$. It is obvious that the correlation between antenna elements changes with frequency, that is, at some frequencies; the correlation becomes 


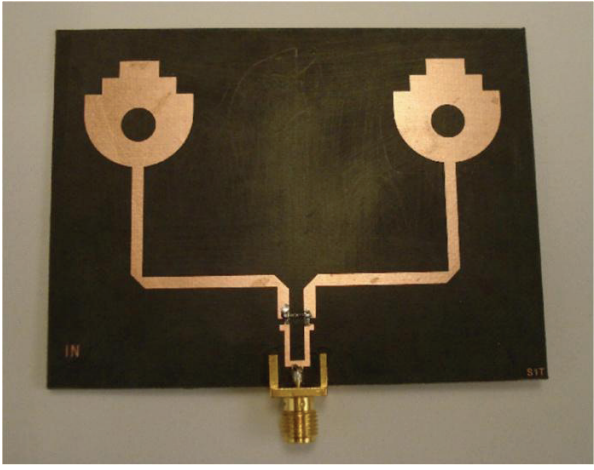

(a)

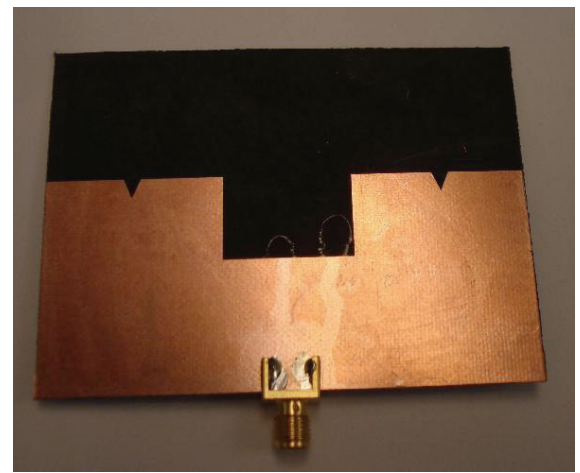

(b)

Figure 11: Fabricated two-element UWB linear antenna array with corporate feed, (a) top view and (b) bottom view.

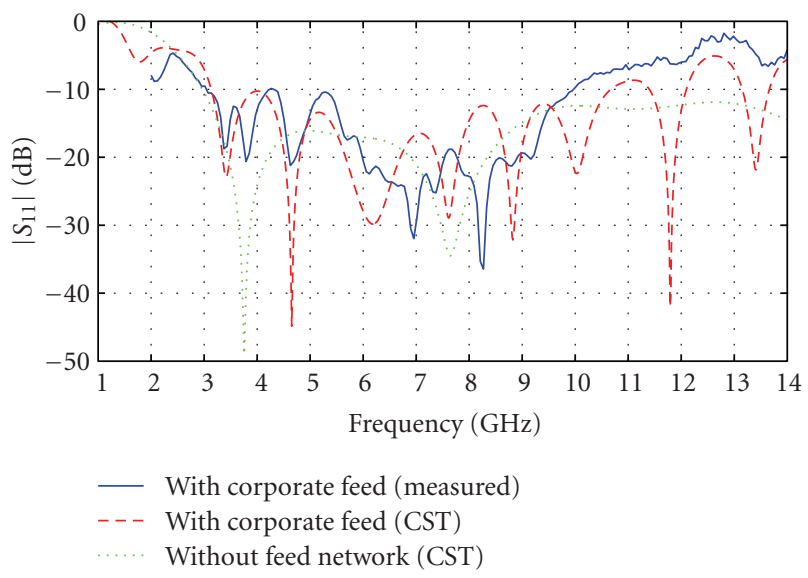

FIgURE 12: Simulated and measured $\left|S_{11}\right|$ curves for the twoelement UWB array prototype with corporate feed $(d=54 \mathrm{~mm})$ compared to the array without feed network.

high while at other frequencies there is no correlation or becomes zero. The average correlation coefficient $\rho_{e}$ between antenna elements is high when the element spacing is small and by increasing element spacing, the average correlation coefficient $\rho_{e}$ decreases.

Figure 7 presents the simulated realized gain curves for the two-element UWB array versus frequency at different

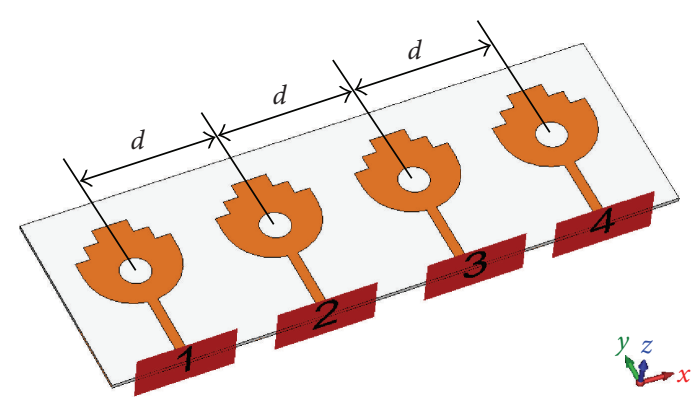

FIgURE 13: Four identical UWB antenna elements fed simultaneously through four independent microstrip lines.

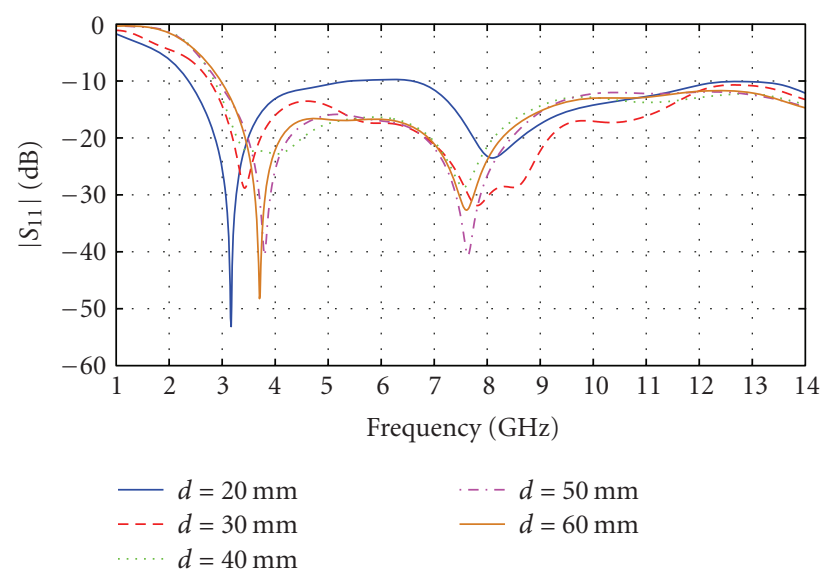

FIgURE 14: Simulated $\left|S_{11}\right|$ results of four-element UWB array.

element spacing values. The strong mutual coupling when $d=20 \mathrm{~mm}$ reduces the array gain at both low and high frequencies. By increasing the element spacing and reducing the effect of mutual coupling, the array gain increases and tends to be more stable across the whole frequency range.

A comparison is carried out in Figure 7 to see which interelement spacing either $28 \mathrm{~mm}$ or $54 \mathrm{~mm}$ is better on the array matching impedance bandwidth or realized gain. It is found that for two-element array, $d=54 \mathrm{~mm}$ is better than $28 \mathrm{~mm}$ for a better matching impedance bandwidth and high stable realized gain across the whole frequency range.

To address the effect of mutual coupling between antenna elements on the array performance compared to a single antenna element, we choose a two-element array with element spacing $d=28 \mathrm{~mm}$ (one wavelength at upper edge frequency $f_{U}=10.6 \mathrm{GHz}$ ) for strong mutual coupling and another array with $d=54 \mathrm{~mm}$ (almost half wavelength at lower edge frequency $f_{L}=3.1 \mathrm{GHz}$ ) for weak mutual coupling. Figure 8(a) shows the reflection coefficient of both antenna arrays compared to those of the single antenna element. In case of array with strong mutual coupling, the matching is enhanced especially at higher frequencies and bandwidth is improved especially at low frequencies while the curve is almost the same as that of single antenna element in case of the array with weak mutual coupling.

The realized gain for both antenna arrays compared to that of the single antenna element is presented in Figure 8(b). 


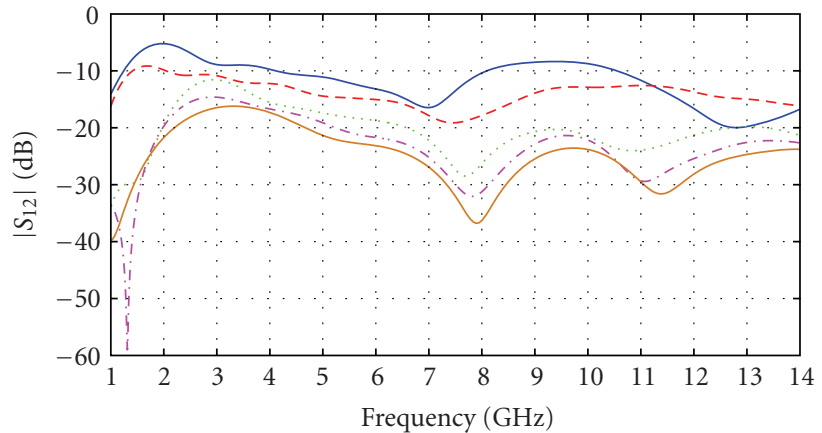

(a)
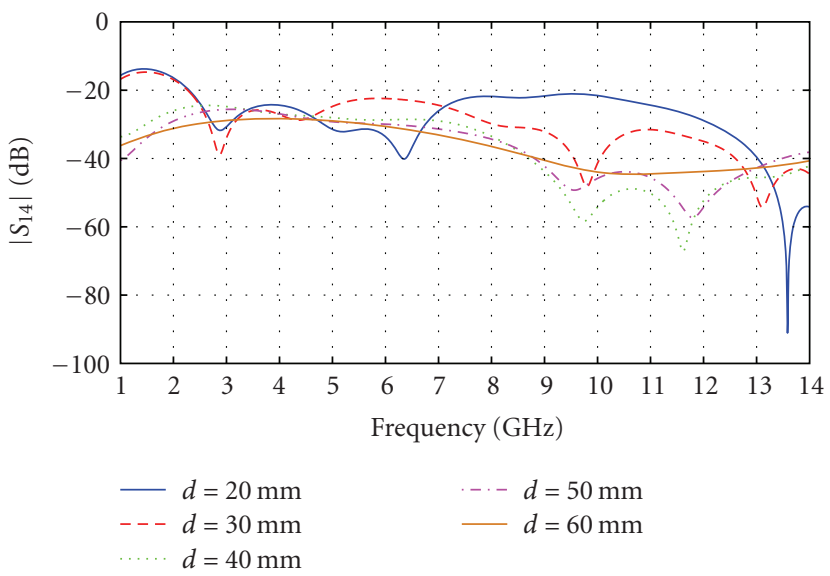

(c)

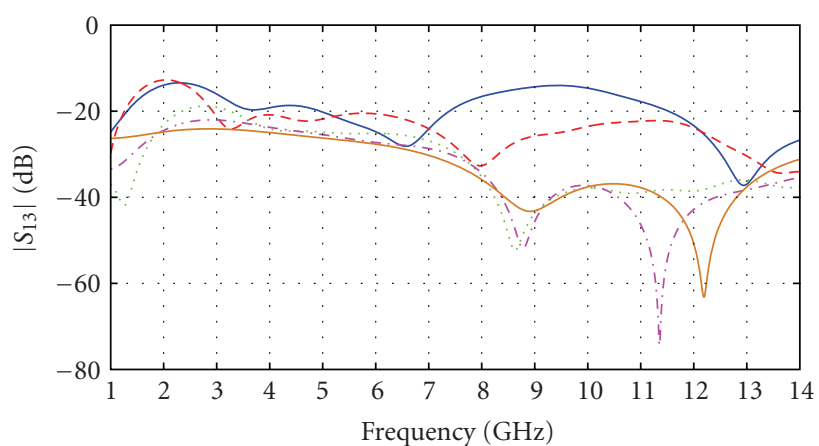

(b)
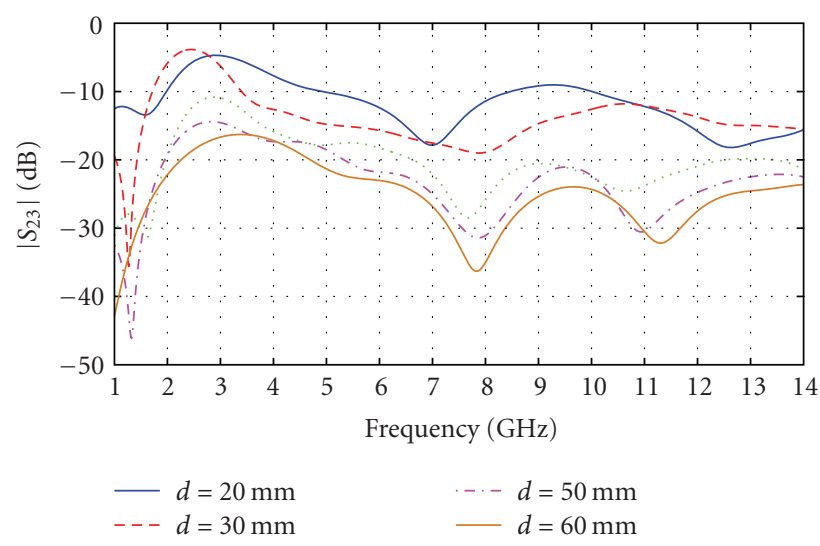

(d)

Figure 15: Simulated (a) $\left|S_{12}\right|$, (b) $\left|S_{13}\right|$, (c) $\left|S_{14}\right|$, and (d) $\left|S_{23}\right|$ results of four-element UWB array.

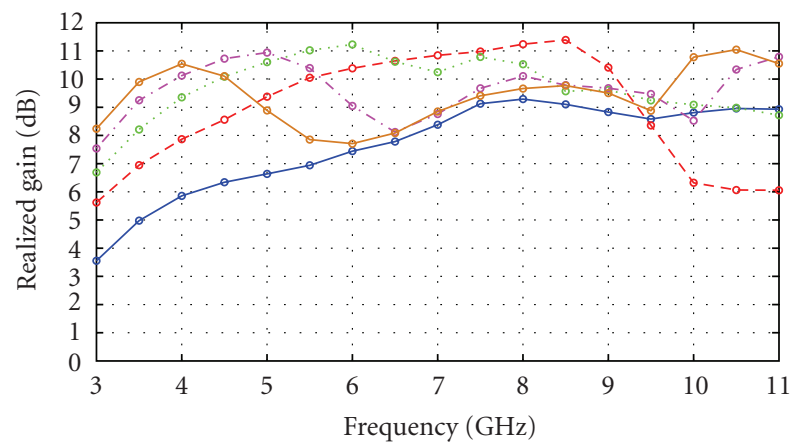

$$
\begin{array}{rlrl}
\because d & =20 \mathrm{~mm} & \because-d=50 \mathrm{~mm} \\
-\bullet-d=30 \mathrm{~mm} & \multimap d=60 \mathrm{~mm} \\
\cdots d=40 \mathrm{~mm} &
\end{array}
$$

FIGURE 16: Simulated realized gain results of four-element UWB array.

The realized gain is increased by almost $3 \mathrm{~dB}$ at most of frequencies in the whole frequency band compared to that of a single antenna element for the array with strong mutual coupling. In case of the array with weak mutual coupling, the realized gain is small and almost reaches that of the antenna element at lower frequencies below $5 \mathrm{GHz}$ and higher frequencies more than $8.5 \mathrm{GHz}$ while the gain is

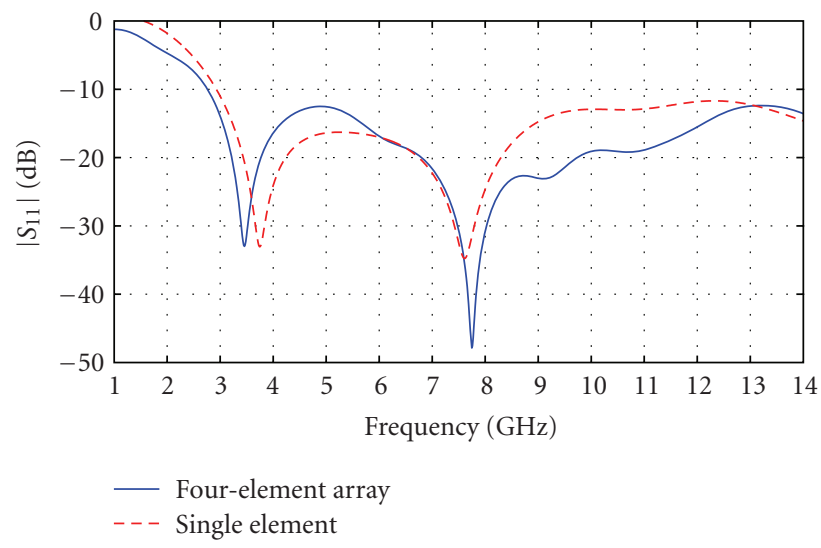

FIGURE 17: Simulated $\left|S_{11}\right|$ curves of the four-element UWB array at element spacing $d=28 \mathrm{~mm}$ compared to a single antenna element.

increased by more than $5 \mathrm{~dB}$ in the midband from $5 \mathrm{GHz}$ to $8.5 \mathrm{GHz}$.

Finally, the $E$-plane $\left(\phi=0^{\circ}\right)$ and $H$-plane $\left(\phi=90^{\circ}\right)$ radiation patterns for both antenna arrays compared to that of the single antenna element at different frequencies 3, 5, 7, and $9 \mathrm{GHz}$, are shown in Figures 9 and 10, respectively. It is obvious that the dipole-like $E$-plane radiation patterns 
are almost the same for both antenna arrays and also for the single antenna element. The $H$-plane radiation patterns which are nearly omnidirectional in case of a single antenna element, become bidirectional for both antenna arrays. The possibility of grating lobes to appear is high in case of large size array $(d=54 \mathrm{~mm})$ compared to the small-size array $(d=28 \mathrm{~mm})$.

Practically, a two-element UWB array prototype with $d=54 \mathrm{~mm}$ is fabricated with corporate feed using $T$ junction power divider. Figure 11 shows the picture of the fabricated array prototype to verify our analysis and simulated results of reflection coefficient $\left|S_{11}\right|$. The effect of using feed network on the array performance is investigated. Figure 12 presents the simulated and measured reflection coefficient $\left|S_{11}\right|$ curves for the two-element UWB array prototype with corporate feed $(d=54 \mathrm{~mm})$ compared to the array without feed network. It is clear that both simulated and measured reflection coefficient $\left|S_{11}\right|$ curves are almost in good agreement but are completely different from those of the array without feed network. Adding the UWB feed network has a great effect on the shape of the reflection coefficient curve without affecting the overall array bandwidth.

\section{Four-Element UWB Linear Antenna Array}

Next, we consider array consisting of four identical UWB antenna elements to further demonstrate our study. Figure 13 shows a four-element UWB array fed by four independent microstrip lines. The substrate and element dimensions are the same as given in the two-element UWB array. The parametric study to show the effect of the element spacing $d$ on the array performance is shown in Figure 14. It is seen that the bandwidth of the four-element array at $d=20 \mathrm{~mm}$ is improved, but the matching becomes worse because of the mutual coupling. Increasing the element spacing does not have much effect on both matching and bandwidth because of the weak mutual coupling.

The other $S$-parameters $\left|S_{12}\right|,\left|S_{13}\right|,\left|S_{14}\right|$, and $\left|S_{23}\right|$, are also studied and presented in Figure 15. Isolation decreases rapidly especially at high frequency for large element spacing values, that is, $d=40,50$, and $60 \mathrm{~mm}$ where the array becomes electrically large. But for small element spacing values, that is, $d=20$ and $30 \mathrm{~mm}$, the mutual coupling effect is strong and hence the isolation does not change too much even at high frequencies.

Figure 16 shows the variation of the array realized gain with different element spacing values versus frequency. It is clear that for a reasonable mutual coupling, the gain is enhanced especially in the midband, but it decreases at both lower and higher frequencies. With increasing the element spacing and decreasing the effect of mutual coupling, the gain increases at almost all frequencies with more stable gain through the whole frequency range.

The reflection coefficient and realized gain of four-element array compared to those of the single antenna element are presented in Figures 17 and 18, respectively. In case of array, the matching is enhanced especially at higher fre-

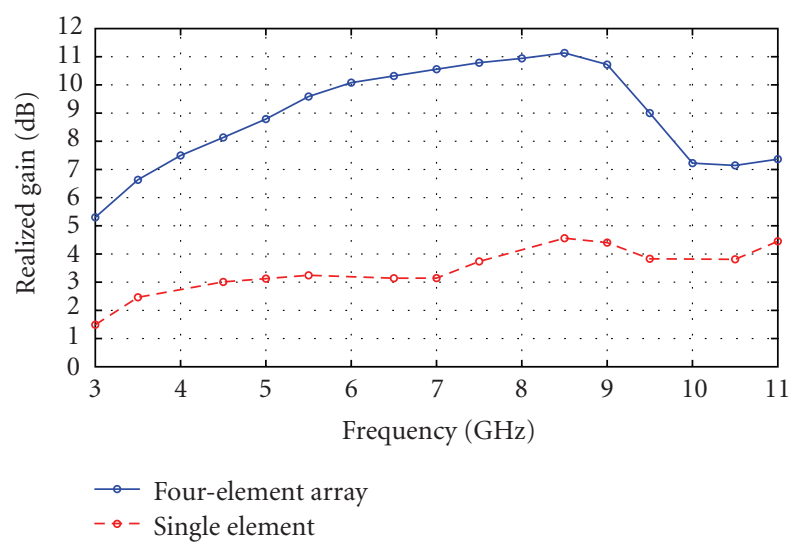

FIGURE 18: Simulated realized gain curves of the four-element UWB array at element spacing $d=28 \mathrm{~mm}$ compared to a single antenna element.

quencies and bandwidth is improved especially at low frequencies compared to that of single antenna element. The realized array gain is increased by almost $6 \mathrm{~dB}$ in the midband from $5 \mathrm{GHz}$ to $8.5 \mathrm{GHz}$ while it increases by a lower rate at lower frequencies below $5 \mathrm{GHz}$ and higher frequencies more than $8.5 \mathrm{GHz}$ as compared to those of a single antenna element.

Finally, the $E$-plane $\left(\phi=0^{\circ}\right)$ and $H$-plane $\left(\phi=90^{\circ}\right)$ radiation patterns for array compared to that of the single antenna element at different frequencies, 3, 5, 7, and $9 \mathrm{GHz}$, are shown in Figures 19 and 20, respectively. It is obvious that the dipole-like $E$-plane radiation patterns are almost the same for array and single antenna element. The $H$-plane radiation patterns, which are nearly omnidirectional in case of a single antenna element, become bidirectional for array.

For the four-element array, small interelement spacing has been chosen, that is, $d=28 \mathrm{~mm}$, to avoid large-size array and to make it easy to simulate in simulation programs.

A four-element UWB array prototype with $d=28 \mathrm{~mm}$ is fabricated with corporate feed using $T$-junction power divider. Figure 21 shows the picture of the fabricated array prototype to verify our analysis and simulated results of reflection coefficient $\left|S_{11}\right|$. The effect of using feed network on the array performance is investigated. Figure 22 presents the simulated and measured reflection coefficient $\left|S_{11}\right|$ curves for the two-element UWB array prototype with corporate feed $(d=28 \mathrm{~mm})$ compared to the array without feed network. It is clear that both simulated and measured reflection coefficient $\left|S_{11}\right|$ curves are almost in good agreement but are completely different from those of the array without feed network. Adding the UWB feed network has a great effect on the shape of the reflection coefficient curve without affecting the overall array bandwidth.

There are a few designs of antenna array for UWB applications $[15,16]$. In [16], only two-element antenna array is introduced with maximum achieved impedance bandwidth of about $83 \%(3.1-7.5 \mathrm{GHz})$. Both two-element and fourelement antenna arrays have been presented in [15]. The achieved gain for the proposed two-element and four-elelemt array in the UWB frequency band is $3.6-8.5 \mathrm{dBi}(4.9 \mathrm{dBi}$ 


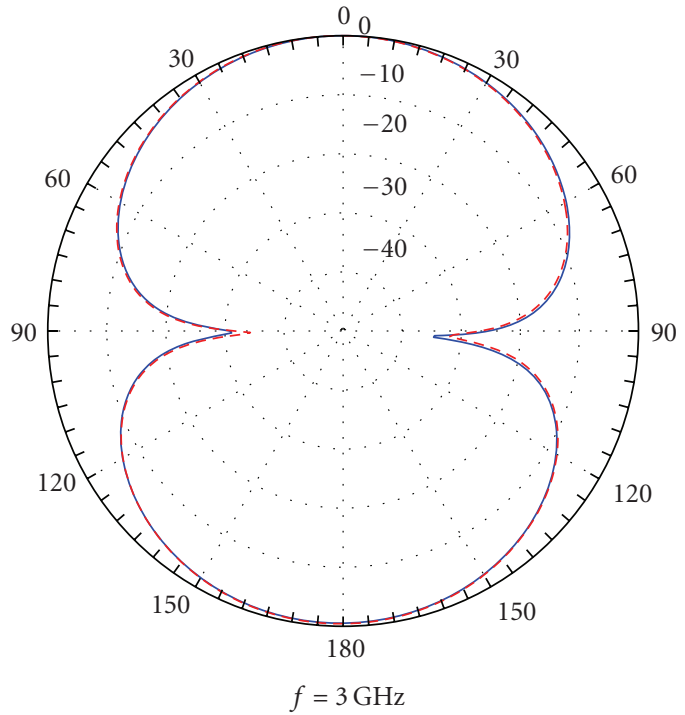

(a)

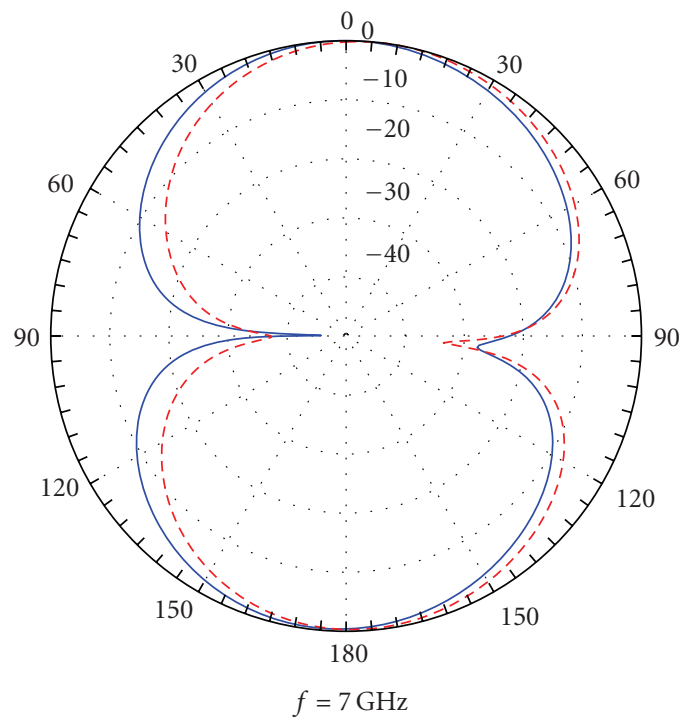

(c)

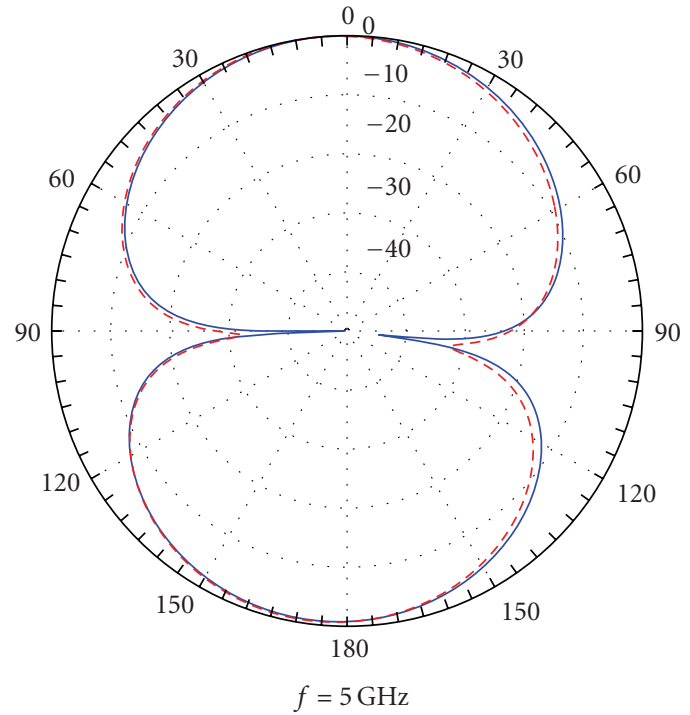

(b)

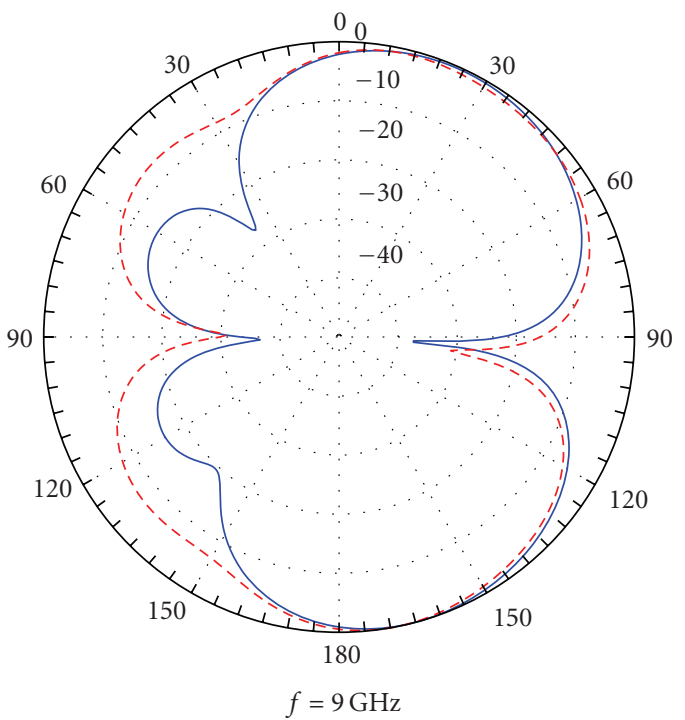

(d)

FIgURE 19: Simulated $E$-plane ( $X Z$-plane) radiation patterns for the four-element UWB array at element spacing $d=28 \mathrm{~mm}($ solid line) compared to a single antenna element (dashed line).

gain variation) and $6.5-10.5 \mathrm{dBi}(4.0 \mathrm{dBi}$ gain variation), respectively. The maximum achieved impedance bandwidth is improved in our proposed designs with less gain variation and more stability in the boresight gain.

\section{Conclusions}

In this paper, mutual coupling effect between array elements of two- and four-element UWB linear arrays on their performances has been studied. For simplicity, it is assumed that both arrays are fed by independent microstrip lines with the same power amplitudes and equal phases. From our study, bandwidth improvement can be achieved for both arrays when the mutual coupling is strong enough or element spacing is small. The mutual coupling also enhances the array realized gain especially in the midfrequency band (5$8.5 \mathrm{GHz}$ ) while it deteriorates the gain outside that frequency range. From the radiation pattern results, it has been shown that the grating lobes appear when the element spacing is greater than two wavelengths at the upper edge frequency $f_{U}=10.6 \mathrm{GHz}$ for UWB arrays. Two fabricated array prototypes with corporate feed have been fabricated and tested to validate the theoretical analysis. The effect of using $T$-junction power divider is clear on the reflection coefficient $\left|S_{11}\right|$. Both simulated and experimental results successfully demonstrate our analysis. 


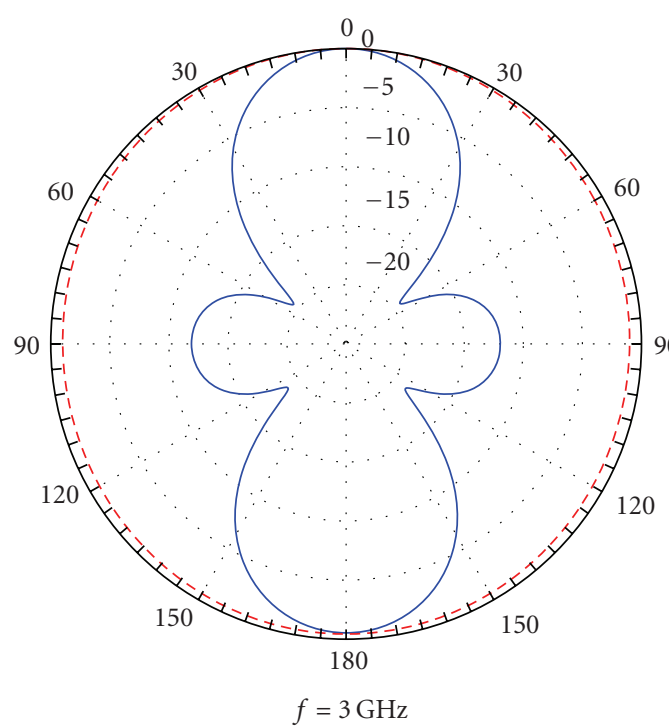

(a)

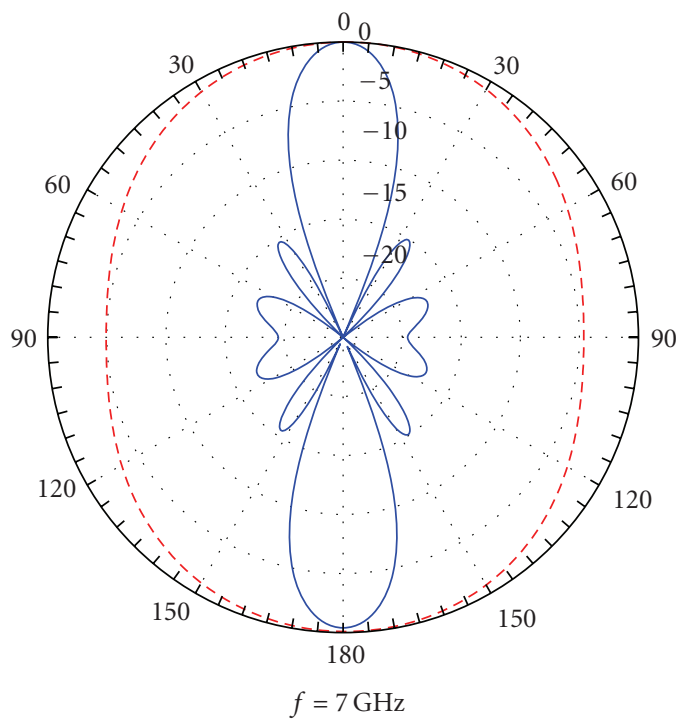

(c)

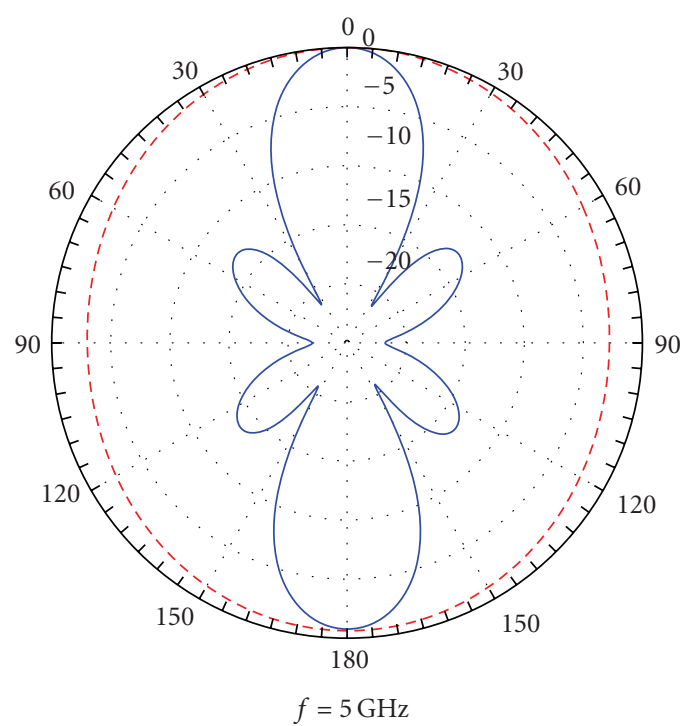

(b)

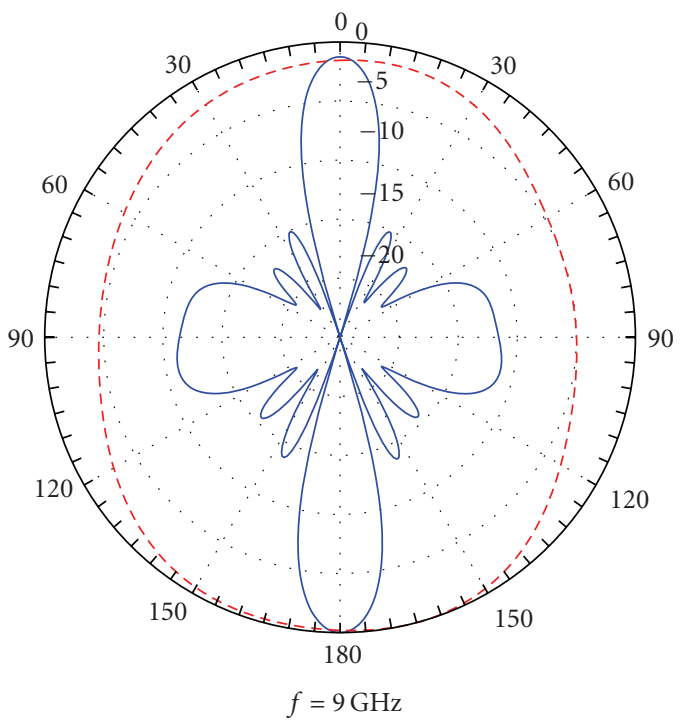

(d)

FIgURE 20: Simulated $H$-plane ( $Y Z$-plane) radiation patterns for the four-element UWB array at element spacing $d=28 \mathrm{~mm}$ (solid line) compared to a single antenna element (dashed line).

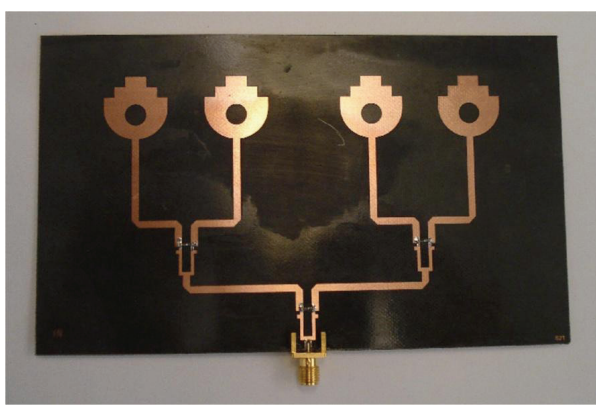

(a)

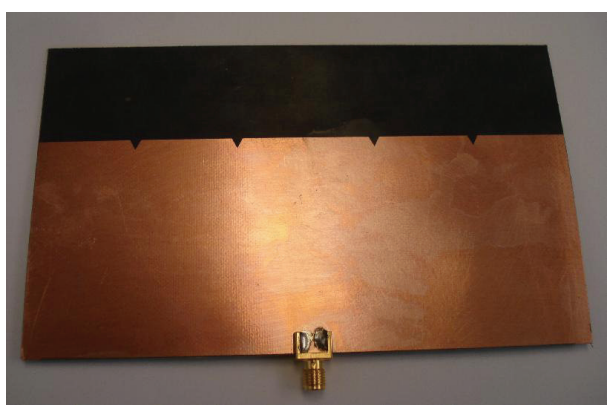

(b)

FIgURE 21: Fabricated four-element UWB linear antenna array with corporate feed ( $T$-junction power divider), (a) top view and (b) bottom view. 


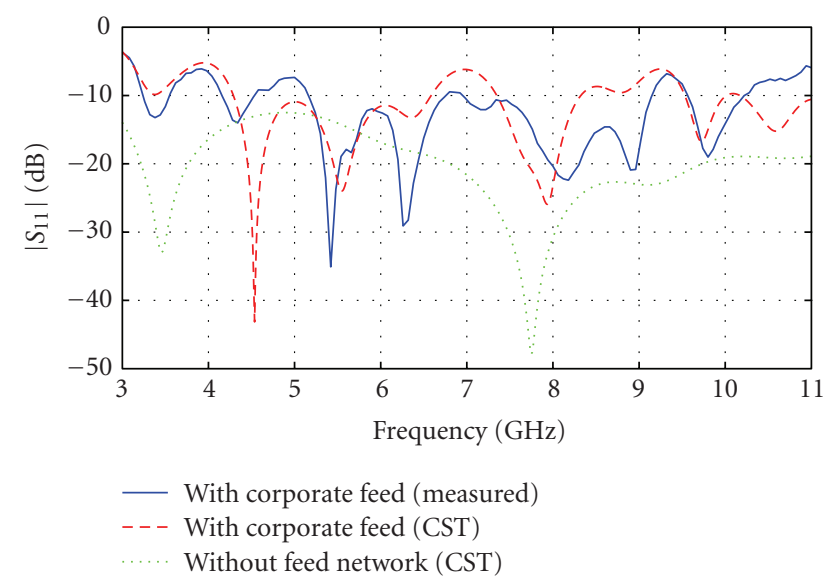

FIGURE 22: Simulated and measured $\left|S_{11}\right|$ curves for the fourelement UWB array prototype with corporate feed $(d=28 \mathrm{~mm})$ compared to the array without feed network.

\section{Acknowledgments}

The first author thanks the Egyptian Ministry of Higher Education and Assiut University in Egypt for their support. The second author thanks the King Saud University (KSU) and the National Plan for Sciences and Technology (NPST) for funds through Research Grant 09ELE858-02.

\section{References}

[1] FCC, "First report and order, revision of part 15 of the commission's rules regarding ultra-wideband transmission system," FCC02- 48, April 2002.

[2] C. C. Chong, F. Watanabe, and H. Inamura, "Potential of UWB technology for the next generation wireless communications," in Proceedings of the 9th IEEE International Symposium on Spread Spectrum Symposium on Spread Spectrum Techniques and Applications, pp. 422-429, August 2006.

[3] R. Zetik, J. Sachs, and R. Thomä, "UWB short-range radar sensing," IEEE Instrumentation and Measurement Magazine, vol. 10, no. 2, pp. 39-45, 2007.

[4] S. Gezici, Z. Tian, G. B. Giannakis et al., "Localization via ultra-wideband radios: a look at positioning aspects of future sensor networks," IEEE Signal Processing Magazine, vol. 22, no. 4, pp. 70-84, 2005.

[5] I. Linardou, C. Migliaccio, J. M. Laheurte, and A. Papiernik, "Twin Vivaldi antenna fed by coplanar waveguide," Electronics Letters, vol. 33, no. 22, pp. 1835-1837, 1997.

[6] S. Y. Chen, P. H. Wang, and P. Hsu, "Uniplanar log-periodic slot antenna fed by a CPW for UWB applications," IEEE Antennas and Wireless Propagation Letters, vol. 5, no. 1, pp. 256259, 2006.

[7] O. Ahmed and A. R. Sebak, "A printed monopole antenna with two steps and a circular slot for UWB applications," IEEE Antennas and Wireless Propagation Letters, vol. 7, pp. 411-413, 2008.

[8] O. M. H. Ahmed, A. R. Sebak, and T. A. Denidni, "Compact UWB printed monopole loaded with dielectric resonator antenna," IET Electronics Letters, vol. 47, no. 1, pp. 7-8, 2011.

[9] A. C. Ludwig, "Mutual coupling, gain, and directivity of an array of two identical antennas," IEEE Transactions on Antennas and Propagation, vol. 24, no. 6, pp. 837-841, 1976.
[10] I. J. Gupta and A. A. Ksienski, "Effect of mutual coupling on the performance of adaptive arrays," IEEE Transactions on Antennas and Propagation, vol. 31, no. 5, pp. 785-791, 1983.

[11] J. A. G. Malherbe, "Analysis of a linear antenna array including the effects of mutual coupling," IEEE Transactions on Education, vol. 32, no. 1, pp. 29-34, 1989.

[12] HFSS, v10, Ansoft Corporation Software, Pittsburgh, PA, USA.

[13] CST Microwave Studio, ver., Computer Simulation Technology, Framingham, MA, 2010.

[14] S. Blanch, J. Romeu, and I. Corbella, "Exact representation of antenna system diversity performance from input parameter description," IEE Electronics Letters, vol. 39, no. 9, pp. 705-707, 2003.

[15] Y. Y. Yang and Q. X. Chu, "Planar 4-element UWB antenna array and time domain characterization," Microwave and Optical Technology Letters, vol. 50, no. 12, pp. 3118-3123, 2008.

[16] H. Z. Liu, J. C. Coetzee, and K. Mouthaan, "UWB antenna array for wireless transmission along corridors," Microwave and Optical Technology Letters, vol. 50, no. 4, pp. 886-890, 2008. 

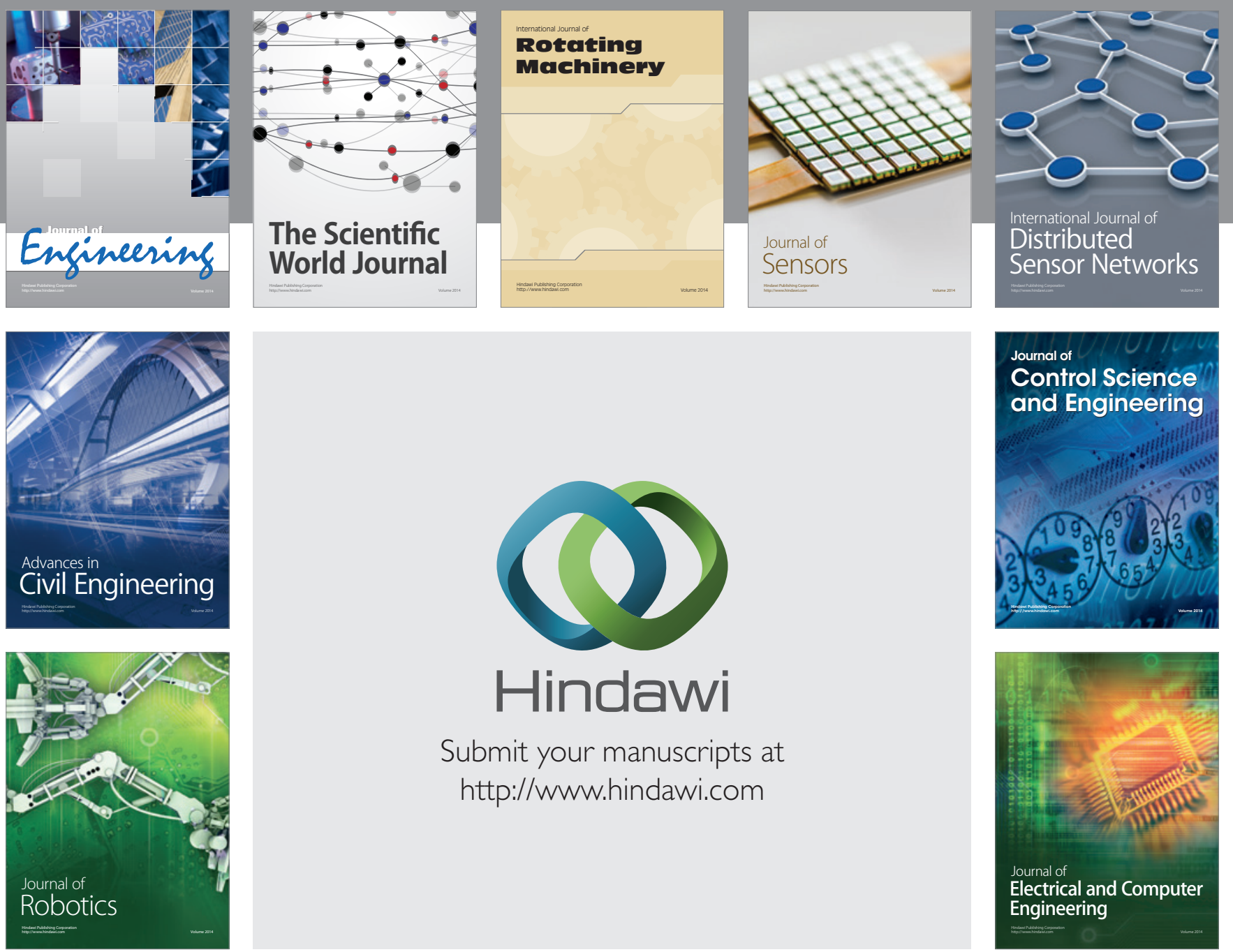

Submit your manuscripts at

http://www.hindawi.com
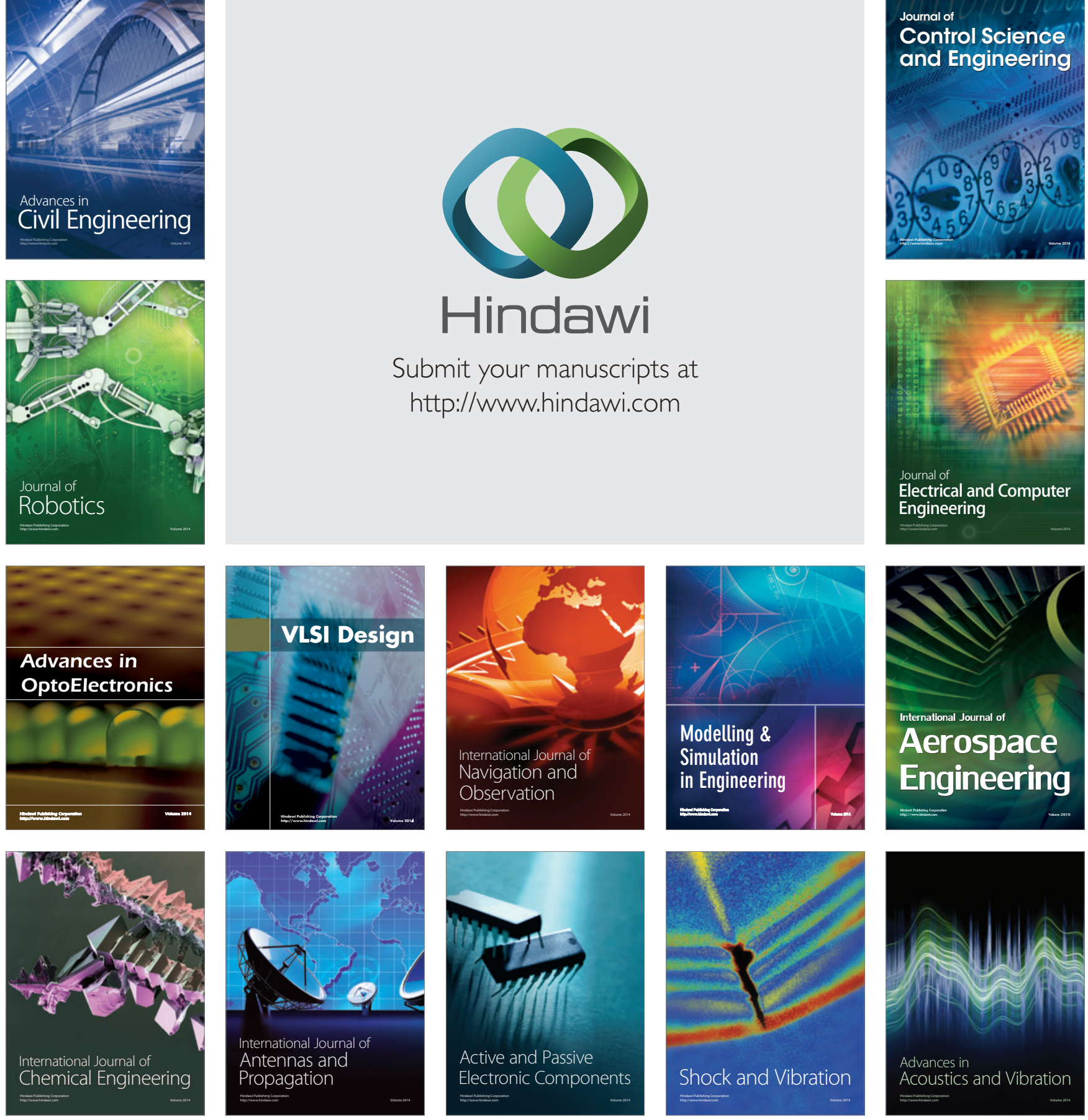